\title{
Management possibilities for increasing the electric steel quality
}

\author{
Mihnea Costoiu ${ }^{1}$, Adrian Ioana ${ }^{1, *}$, Augustin Semenescu ${ }^{1}$, Dragos Marcu ${ }^{1}$ and Massimo \\ Polifroni ${ }^{2}$ \\ ${ }^{1}$ University Politehnica of Bucharest, Spl. Independentei 313, Bucharest, Romania \\ ${ }^{2}$ University of Turin, Via Verdi, 8 - 10124 Turin, Italy
}

\begin{abstract}
The article presents the technological advances and modernizations carried out at national and / or world level in the field of increasing the electric steel quality. In this context, conventional complex steel processing methods are analyzed outside the electric arc furnace, in order to increase the electric steel quality. Special non-conventional procedures for the production of quality steels are also presented. The progress achieved in the field of steel production, mainly aimed at increasing productivity and quality, had as a basic premise the "secondary metallurgy" or the treatment of the metal outside the primary production aggregate (furnace or converter). This concept involves transforming the furnace or the converter into a specialized fast-melting aggregate, the rest of the processes specific to advanced steel refining being carried out in pots (which is why the "pot metallurgy" denomination is also used). We will also present in the article a revolutionary concept for the steel production in the electric arc furnace, a procedure which is the subject of a patent application belonging to the authors of this article, applying the pyramid effect for the steel production in the electric arc furnace.
\end{abstract}

\section{Introduction}

Lately, the progresses achieved in the field of steel elaboration, mainly aimed at increasing productivity and quality, have had as a basic prerequisite the "secondary metallurgy" or the metal treatment outside the primary elaboration aggregate (furnace or converter). This concept involves transforming the furnace or convertor into a fast-melting specialized aggregate, the rest of the advanced steel refining processes being carried out in pots (which is why we use the denomination of "metallurgy in the pot").

Usually, metal processing in the pot takes place in a neutral or reducing atmosphere and aims to achieve the following objectives (separately or together, [1-2]):

- homogenizing the temperature and chemical composition of the steel;

- alloying of the steel in a narrow area of the chemical composition;

- steel deoxidation;

- reduction of the non-metallic inclusions content;

- desulphurization;

\footnotetext{
*Corresponding author : adyioana@gmail.com
} 
- $\quad$ reduction of gases content in the steel $([\mathrm{H}],[\mathrm{N}])$;

- reduction of the undesirable additions content;

- reaching a prescribed grain size;

- correction of the steel temperature to achieve the casting temperature.

In order to obtain one or more of the above mentioned effects, we can apply processes such as: insufflation of steel with inert gases, induction stirring, vacuum treatments, insufflation of pulverulent additions (for refining, deoxidation and alloying), heat input treatment $[3,4]$ (heating by the electric arc or induction currents).

\section{Conventional complex methods for steel processing outside the electric arc furnace}

Sparging/Spraying/bubbling gas treatment is the simplest way for the steel secondary treatment in the casting pot. We primarily aim at homogenizing the melt (composition and temperature) and at increasing the steel purity. Several sparging/spraying/bubbling systems are applied: through porous bricks (buffers/stoppers) placed in the bottom or wall of the pot, through a submerged lance.

Injection treatment (powder insufflation) primarily aims at increasing the steel quality through advanced deoxidations. As injecting substances, the calcium-containing alloys and the high basicity slags have proven to be effective.

Heating steel in the pot furnace, not being a treatment itself, aims to compensate for the thermal losses during the actual treatment. The machine used for this technological process is the " furnace pot " either in its simple form LF ("Ladle Furnace") or in complex form (of VAD type).

The use of the vacuum is a very widespread technique, and it is used in order to increase quality by intensifying the decarburization, degassing, vaporization and reduction of oxide suspensions. The effect differs depending on the treatment method, the main purpose being to decrease the content of $[\mathrm{O}],[\mathrm{C}],[\mathrm{H}]$ and $[\mathrm{N}]$.

For the steel elaboration practice, it is important to degas the casting jet (the BVBochumer-Verein process) and in particular to degas the partial quantities. The degassing processes of the partial quantities are the following:

- the vacuum recirculation process (the RH, "Ruhrstahl-Heraeus" process when it appeared and the " Henrichshutte Refining-process at present);

- the vacuum lifting process (the DH, "Dortmund-Horder process).

According to the world-wide trends and those applied in the country, the modern solutions for improving the RH process performance can be systematized in this way [5]:

- oxygen insufflation through the immersed hole (RH-OB);

- diversification of the gaseous agents for the steel entraining through the alternative use of the reactive gases $\left(\mathrm{N}_{2}, \mathrm{CO}_{2}\right)$;

- use of carbon dioxide post-combustion in the vacuum chamber;

- workspace resizing in order to increase the flow of recirculated liquid steel;

- increase of the vacuum pump suction capacity;

- degassing control by using the mass spectrometer.

In Figure 1 we present schematically the pot degassing processes: simple sparging/spraying/bubbling with inert gas (a), the VAD (Vacuum Argon Decarburization) process (b) and the VOD (Vacuum Oxygen Decarburation) process (c).

The ASEA - SKF Process (vacuum refining with heat input and electromagnetic stirrer) was first applied in Sweden, and was subsequently expanded and improved in Japan by Kavasaki Steel Corporation, where it became the LD - LRF process (Ladle Refining Furnace- refining pot-furnace). 

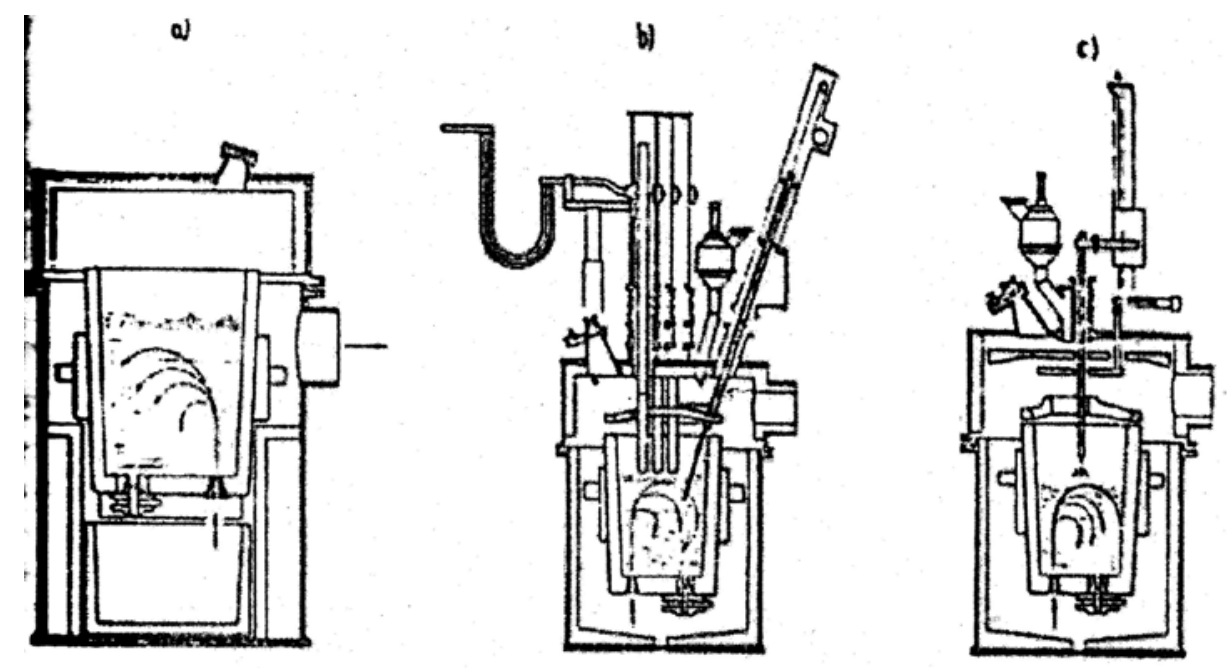

Fig. 1. Pot degassing processes:

$\mathrm{a}$ - simple sparging/spraying/bubbling with inert gas; $\mathrm{b}$ - the VAD process; $\mathrm{c}$ - the VOD process.

The VAD-FINKL Process (vacuum refining with heat input and argon sparging/spraying/bubbling) was performed by Finkel \& Sons Inc., Chicago-USA. Figure 2 presents the principle scheme of the pot furnace from the VAD-FINKL installation.

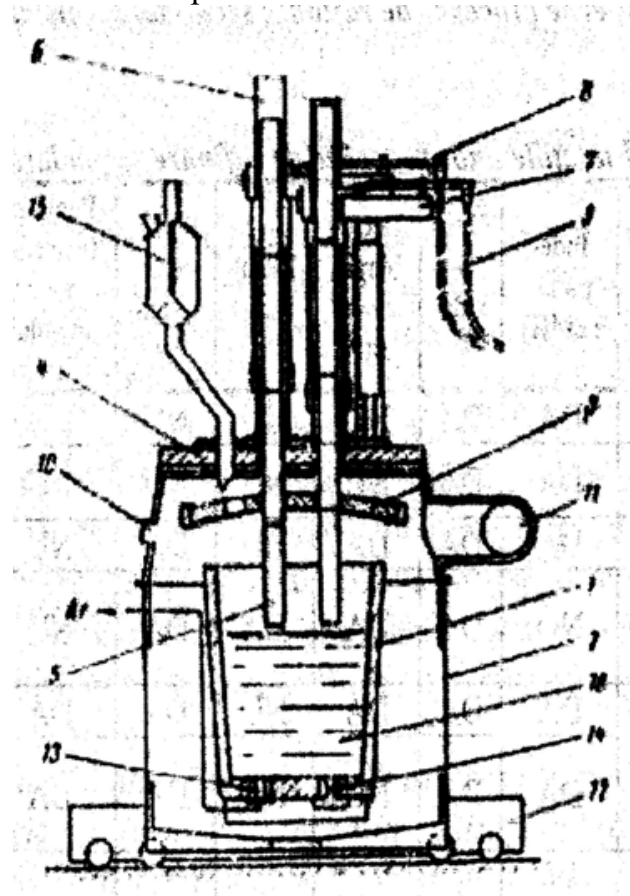

Fig. 2. The principle scheme of the pot furnace from the VAD-FINKL installation.

1 - pot; 2 - vacuum recipient; 3 - pot lid (screen); 4 - sealed lid; 5 - graphite electrode; 6 - guide line; 7 - electrode holder arm; 8 - copper bar; 9 - flexible cable; 10 - peephole; 11 - suction line; 12 - transfer car; 13 - porous buffer/stopper; 14 - lock with tray; 15 - dosing device; 16 metallic bath. 
Table 1. Functions of steel secondary refining processes.

\begin{tabular}{|c|c|c|c|c|c|c|c|}
\hline Process & $\begin{array}{l}\text { Remo- } \\
\text { val of } \\
{[\mathrm{H}]}\end{array}$ & $\begin{array}{l}\text { Deo- } \\
\text { xidation }\end{array}$ & $\begin{array}{l}\text { Advanced } \\
\text { Decar- } \\
\text { burization }\end{array}$ & $\begin{array}{l}\text { Desul- } \\
\text { phuriza } \\
\text {-tion }\end{array}$ & $\begin{array}{l}\text { Reduc- } \\
\text { tion of } \\
\text { oxides }\end{array}$ & $\begin{array}{l}\text { Adjusting } \\
\text { the } \\
\text { temperatu } \\
\text {-re of the } \\
\text { liquid } \\
\text { steel }\end{array}$ & Characteristics \\
\hline$\overline{\mathrm{DH}}$ & YES & YES & $\mathrm{NO}$ & $\mathrm{NO}$ & $\mathrm{NO}$ & $\mathrm{NO}$ & \multirow[t]{2}{*}{$\begin{array}{l}\text { Fast degassing, low temperature } \\
\text { drop, correct alloying }\end{array}$} \\
\hline $\mathrm{RH}$ & YES & YES & $\mathrm{NO}$ & $\mathrm{NO}$ & $\mathrm{NO}$ & $\mathrm{NO}$ & \\
\hline VOD & YES & YES & YES & $\mathrm{NO}$ & YES & NO & \multirow{2}{*}{$\begin{array}{l}\text { Obtaining steels with very low } \\
\text { content of } \\
\text { carbon; large recovery of } \mathrm{Cr} \text {; high } \\
\text { productivity }\end{array}$} \\
\hline AOD & $\mathrm{NO}$ & YES & YES & YES & YES & $\mathrm{NO}$ & \\
\hline $\begin{array}{l}\text { VAD- } \\
\text { FINKL } \\
\end{array}$ & YES & YES & YES & NO & YES & YES & \multirow{2}{*}{$\begin{array}{l}\text { Refining in vacuum } \\
\text { Desulfurization } \\
\text { Decanting non-metallic inclusions } \\
\text { Temperature adjustment }\end{array}$} \\
\hline $\begin{array}{l}\text { ASEA- } \\
\text { SKF }\end{array}$ & YES & YES & NO & YES & YES & YES & \\
\hline $\begin{array}{l}\text { Thysse } \\
\text { n- } \\
\text { Niederh } \\
\text { ein } \\
\text { (TN) } \\
\text { Ca } \\
\text { injecti- } \\
\text { on } \\
\end{array}$ & NO & YES & NO & YES & NO & NO & $\begin{array}{l}\text { Quick reduction of }[\mathrm{O}] \text { and }[\mathrm{S}] \text {, } \\
\text { decanting of non-metallic } \\
\text { inclusions }\end{array}$ \\
\hline
\end{tabular}

\section{Special non-conventional processes for quality steels elaboration}

In all the cases in which for the steel-elaboration a pot metallurgy intervention is required, combinations of processes are used: gas sparging/spraying/bubbling, insufflation, heating, vacuum treatment, and the use of (Al) wires in the form of coils. Steel elaboration in the future, and especially high-quality steel elaboration, involves both the increase of technical developments and existing processes and the introduction of new, more efficient processes.

Plasma arc heating will be used over the next decades to elaborate high-quality steels where the control and yields of plasma arc furnaces can save costly raw materials. A process such as this, developed in the pilot phase in England by Foster Wheeler, is the plasma arc rotating furnace.

The Plasmasmelt process has as main feature the use of the plasma jet burner.

The continuous steel elaboration has as its starting point the increase of the chemical reactions rates by augmenting the reaction surface in the same volume. Thus, metallurgists are beginning to think about reactors (elaboration aggregates) that can handle fine metallic materials. One such example is the ELRED Swedish process, developed by SKB-Stora Kopparbergs Bergslags from Sweden, together with ASEA from Sweden and Luirgi from RFG. The basic principle of this process consists in the prereduction of the iron ore in a fluidized bed and the final reduction in the electric arc furnace, which operates with continuous current.

The Dored process was initiated by the same Swedish company SKB and is based on the principle of the Kaldo process. 
Other non-traditional processes, researched especially by Swedish firms, are these: the Eketrop-Vollak process (converter type reactor), the S-N process, the Inred process (Boliden AB, Sweden), the Rotored process (rotating reactor), the KR process (Korf Stahl, RFG).

Another process, designed to increase the aggregates productivity, the economicity of technological processes and steel quality, is the GRAF process (developed in a new aggregate called GRAF). The GRAF aggregate cumulates, according to some basic principles, two aggregates: an electric arc furnace and a gas refining installation outside the furnace. The industrial experiments performed on the 3t GRAF aggregate have shown that the new process is stable and provides regulated control of the temperature and chemical composition.

The Pains Brazilian siderurgical company (CSP) put into operation the first $30 \mathrm{t}$ EOF furnace (Energy Optimizing Furnace), replacing four SM furnaces of the same capacity. The principle of the EOF process is schematically shown in Figure 3.

The EOF process is a vertical process for the steel elaboration, in counter current. The oxygen is injected above the bath and combines with carbon to give rise to carbon dioxide, which is therefore burned above the bath. The hot gases pass through an old iron preheater (load), preheating it at about $800^{\circ} \mathrm{C}$. Thus, by replacing the electric energy with oxygen (insufflated through the lance and oxyfuel burners) and carbon, important savings are achieved.

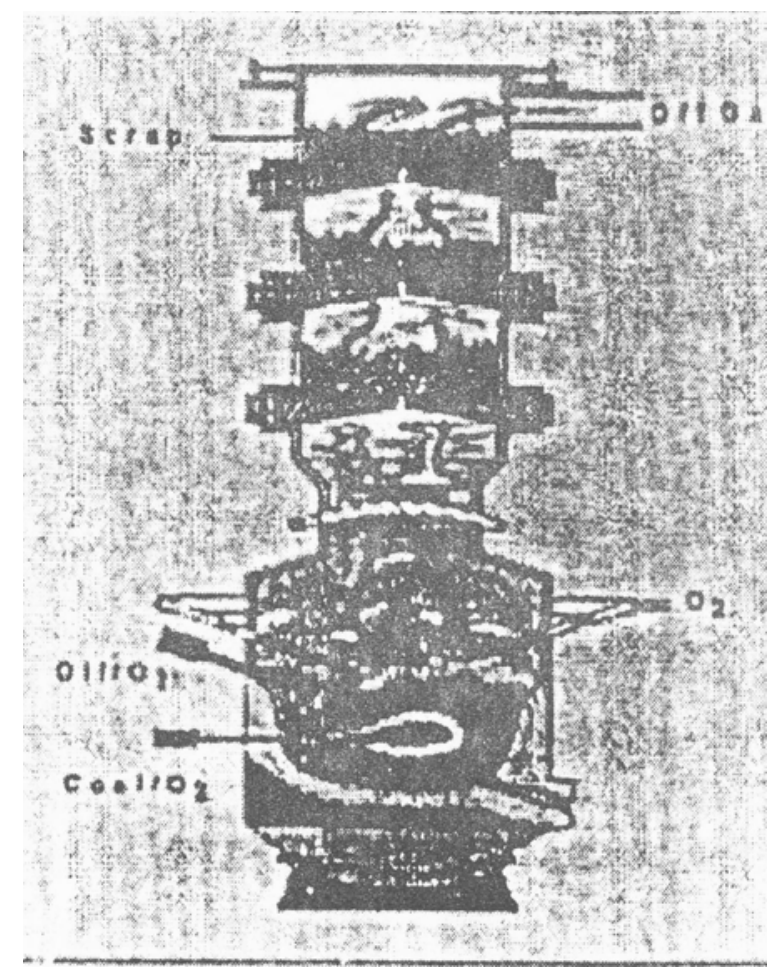

Fig. 3. The EOF Process.

Steel elaboration by nuclear energy may lead in the future to a method in which the energy of the nuclear reactions is used indirectly and efficiently in this respect. The problem is that only the transformation of the nuclear reactions energy in the form of heat is known in the present technology, and due to material boundaries, the high temperature heat cannot be used. 
The dry elaboration of steel is a concept that was applied in production in 2010. This new technology involves refining and pressing without melting. A pilot station line is under study at UOP (Universal Oil Products) for the manufacture of iron powder.

\section{Conclusions}

We can conclude that the achievement of the main objectives for increasing the electric steel quality (homogenization of temperature and chemical composition, reduction of the content of non-metallic inclusions and gases and obtaining a precise grain size) involves two categories of processes:

A. Conventional complex processes for the steel processing outside the electric arc furnace.

B. Special non-conventional elaboration processes.

The use of the vacuum and / or insufflation (injection) of pulverulent materials into the liquid steel presents for us the most used methods of steel processing outside the primary elaboration aggregate (secondary metallurgy).

Of the special non-conventional elaboration processes, the continuous elaboration of the steel (the ELRED process) is distinguished. Nuclear power elaboration or dry elaboration are pilot- tested concepts and methods, but still in the future, from an industrial viewpoint.

The expansion of the secondary processing installations demonstrates the possibilities of the pot metallurgy to improve the competitiveness of the products processed on this flow.

The development of the elaboration technologies involves both the improvement of the aggregates construction (primary and secondary), including the quality improvement of the refractory materials, as well as the optimization of the interaction among the different technological elements.

\section{References}

1. A. Ioana, N. Constantin, P. Moldovan, IOP Conference Series: Materials Science and Engineering, 85, 1 (2015)

2. M. Costoiu, A. Ioana, A. Semenescu, D. Marcu, IOP Conference Series: Materials Science and Engineering, 161, 012104 (2016)

3. A. Ioana, A. Preda, A., L. Beşea, P. Moldovan, N. Constantin, U.P.B. Sci. Bull., Series $\mathrm{B}, \mathbf{7 8}, \mathbf{3}, 185$ (2016)

4. A. Ioana, N. Constantin, P. Moldovan, IOP Conference Series: Materials Science and Engineering, 85, 1(2015)

5. A. Ioana, A. Semenescu, C.F. Preda, The Journal of American Business Review, Cambridge, 2, 2, 159, (2014) 